\title{
The features of AECOPD with carbon dioxide retention
}

\author{
Xia Wei ${ }^{1,2}$, Nan Yu ${ }^{3}$, Qi Ding ${ }^{2}$, Jingting Ren ${ }^{2}$, Jiuyun $\mathrm{Mi}^{2}$, Lu Bai ${ }^{1}$, Jianying $\mathrm{Li}^{4}, \mathrm{Min}_{\mathrm{Qi}}{ }^{5}$ and Youmin Guo ${ }^{1^{*}}$ (D)
}

\begin{abstract}
Background: Chronic obstructive pulmonary disease (COPD) with carbon dioxide retention is associated with a worsening clinical condition and the beginning of pulmonary ventilation decompensation. This study aimed to identify the factors associated with carbon dioxide retention.

Methods: This was a retrospective study of consecutive patients with COPD (meeting the Global Initiative for Chronic Obstructive Lung Disease diagnostic criteria) hospitalized at The Ninth Hospital of Xi'an Affiliated Hospital of Xi'an Jiaotong University between October 2014 and September 2017. The baseline demographic, clinical, laboratory, pulmonary function, and imaging data were compared between the 86 cases with carbon dioxide retention and the 144 cases without carbon dioxide retention.

Results: Compared with the non-carbon dioxide retention group, the group with carbon dioxide retention had a higher number of hospitalizations in the previous 12 months $(p=0.013)$, higher modified Medical Research Council (mMRC) dyspnea scores $(p=0.034)$, lower arterial oxygen pressure $(p=0.018)$, worse pulmonary function (forced expiratory volume in one second/forced vital capacity [FEV $\left.1 / \mathrm{FVC}_{;} p<0.001\right]$, FEV $\%$ pred $[p<0.001]$, Z5\%pred [ $p=0.004]$, R5\%pred [ $p=0.008]$, R5-R20 [p=0.009], X5 $[p=0.022]$, and $\mathrm{Ax}[p=0.011]$ ), more severe lung damage (such as increased lung volume $[p=0.011]$, more emphysema range $[p=0.007]$, and lower mean lung density $[p=0.043])$. $\mathrm{FEV}_{1}<1 \mathrm{~L}$ (odds ratio $[\mathrm{OR}]=4.011,95 \%$ confidence interval [Cl]: 2.216-7.262) and emphysema index $(E \mathrm{EI})>20 \%(\mathrm{OR}=1.926,95 \% \mathrm{Cl}: 1.080-3.432)$ were independently associated with carbon dioxide retention in COPD.
\end{abstract}

Conclusion: Compared with the non-carbon dioxide retention group, the group with carbon dioxide retention had different clinical, pulmonary function, and imaging features. $\mathrm{FEV}_{1}<1 \mathrm{~L}$ and $\mathrm{EI}>20 \%$ were independently associated with carbon dioxide retention in AECOPD.

Trial registration: ChiCTR-OCH-14004904. Registered 25 June 2014.

Keywords: Acute exacerbation, Chronic obstructive pulmonary disease, Pulmonary function test, Emphysema index, Carbon dioxide retention

\section{Background}

Chronic obstructive pulmonary disease (COPD) is the fourth leading cause of death worldwide and is expected to be the third leading cause of death by 2020 [1]. COPD is also a major chronic disease that produces a large economic and social burden worldwide [2]. In China, COPD is a major contributor to the overall morbidity and mortality burden owing to the relatively high prevalence of

\footnotetext{
* Correspondence: guoyoumin163@sina.com

${ }^{1}$ Department of Radiology, Xi'an Jiaotong University Medical College First Affiliated Hospital, Xi'an, China

Full list of author information is available at the end of the article
}

smoking and rising environmental pollution [3, 4]. There are limited treatments available for the effective prevention of COPD progression. Respiratory failure secondary to AECOPD can lead to disease progression. Therefore, distinguishing patients with a risk of carbon dioxide retention is of clinical importance in the management of acute exacerbation of chronic obstructive pulmonary disease (AECOPD).

Since COPD is a heterogeneous disease, it is difficult for a single indicator to reflect all features of the disease. Pulmonary function indicators, especially $\mathrm{FEV}_{1}$ (forced expiratory volume in $1 \mathrm{~s}$ ), are recognized as important

(C) The Author(s). 2018 Open Access This article is distributed under the terms of the Creative Commons Attribution 4.0 International License (http://creativecommons.org/licenses/by/4.0/), which permits unrestricted use, distribution, and 
because they can reflect one of the key characteristics of COPD - airflow limitation, but according to the Global Initiative for Chronic Obstructive Lung Disease (GOLD) update in 2017 [5], $\mathrm{FEV}_{1}$ was used for grading of disease severity but was not a variable used to guide treatment. Other well accepted indicators include 64-detector computed tomography (CT) parameters such as bronchial wall thickness and emphysema index (EI), which reflect COPD pathological changes [6,7], airway wall thickening, and airway remodeling response. Emphysema index refers to the proportion of low-density areas less than $950 \mathrm{HU}$ occupying the lung volume. An increase in the emphysema index reflects an increase in the extent of parenchymal destruction of the lungs. Yamasawa [8] reported that CT could be used as a non-invasive tool to predict aerobic capacity in COPD.

Another indicator that holds promise for assessing the severity of COPD is carbon dioxide retention. Carbon dioxide retention indicates the exhaustion of lung reserve, loss of ventilatory function, worsening of clinical symptoms, respiratory failure, and secondary damage. But actually we don't know the complete long term consequences of hypercapnia [9]. Tsuboi [10] reported that persistent carbon dioxide retention in chronic ventilatory deficient subjects may reflect an adaptive mechanism that allows for lower levels of alveolar ventilation so as not to overload the respiratory muscles. In summary, carbon dioxide retention is involved in the respiratory center drive capacity, respiratory muscle strength, airway obstruction, pulmonary parenchymal damage, and many other complex processes. The gold standard for carbon dioxide retention is arterial blood gas analysis, but arterial blood gas analysis only reflects the instantaneous partial pressure of carbon dioxide in the blood. Therefore, checking blood gas at different times will produce different results, and the overall extent of COPD disease leading to carbon dioxide retention (or even respiratory failure) cannot be determined accurately. Accurate prediction of COPD carbon dioxide retention from pathological changes level would be of great help in disease monitoring.

What is the relationship between carbon dioxide retention and pulmonary function and imaging parameters? To date, this relationship has not been clear. For this study, we were interested in the ability to predict and estimate carbon dioxide retention using pulmonary function parameters and imaging parameters. Therefore, the aims of the present study were: 1) to compare the differences in clinical symptom scores, inflammatory markers, pulmonary function indicators, and CT parameters between patients with carbon dioxide retention in COPD vs those without carbon dioxide retention; and 2) to identify the factors associated with carbon dioxide retention in AECOPD.

\section{Methods}

\section{Study design and subjects}

This study was a retrospective study of consecutive AECOPD patients admitted to the Department of Respiratory Medicine of The Ninth Hospital of Xi'an Affiliated Hospital of Xi'an Jiaotong University from October 2014 to September 2017, meeting the GOLD diagnostic criteria $\left(\mathrm{FEV}_{1} / \mathrm{FVC}<70 \%\right.$ bronchodilators inhaled). AECOPD refers to patients who have COPD symptoms (cough, sputum, shortness of breath, etc.) exacerbating the need for hospitalization. These patients are typically treated with a short acting bronchodilator, antibiotics, and / or a glucocorticoid. Exclusion criteria were as follows: 1) < 40 years of age; 2) pregnant women; 3) lung diseases such as lung cancer, pneumonia, active tuberculosis, pulmonary embolism, or interstitial lung disease; 4) previous pulmonary surgery; 5) unable to complete the pulmonary function test; 6) asthma, severe heart, liver, or kidney dysfunction; 7) CT images of insufficient quality for analysis; 8 ) other causes of respiratory failure such as obstructive sleep apnea syndrome; 9) Inclusion of AECOPD patients did not use NIV before blood gas analysis; and 10) prehospital treatment that included glucocorticoids or antibiotics.

This is a subgroup of the "Digital Lung" disease assessment system and diagnostic criteria (201402013) approved by the Chinese Society for Clinical Research (Grant No.: ChiCTR-OCH-14004904). The study was approved by the Ninth Hospital of Xian ethics committee (No.2014001). Written informed consent was obtained from all patients.

\section{Grouping}

Among the included patients with AECOPD, those with arterial carbon dioxide partial pressure greater than $45 \mathrm{mmHg}$ were assigned to the carbon dioxide retention group. Patients with arterial carbon dioxide partial pressure less than $45 \mathrm{mmHg}$ were assigned to the non-carbon dioxide retention group (control group). The $45 \mathrm{mmHg}$ was chosen as the threshold, rather than the diagnostic threshold of $50 \mathrm{mmHg}$ for type II respiratory failure, because our interest was to study the differences in the characteristics of people with carbon dioxide retention and those without carbon dioxide retention. Of course, for treatment, this threshold is low, but for the study of carbon dioxide retention, we believe that the key point of ventilatory decompensation is more suitable, that is, arterial blood gas carbon dioxide partial pressure $45 \mathrm{mmHg}$. In addition, according to AECOPD treatment recommendations [11], $\mathrm{PaCO} 2 \geq 45 \mathrm{mmHg}$ can also be used as a threshold for non-invasive ventilation treatment.

\section{Clinic and biochemistry data collection}

A questionnaire was used to collect data on the participants' sex, age, smoking status, body mass index (BMI), 
number of hospitalizations caused by AECOPD during the previous 12 months, the COPD Assessment Test (CAT), and the modified Medical Research Council (mMRC) dyspnea index at admission. Blood gas analysis was performed within 1 day of admission using a RADIOMETER ABL automatic blood gas analyzer (ABL800, RADIOMETER, Copenhagen, Denmark).

\section{Pulmonary function test (PFT)}

Spirometry and impulse oscillometry (IOS) (MasterScreen, JAEGER, Germany) were performed before discharge. The maximum expiratory flow-volume curve, forced vital capacity, pulmonary diffusion function in one breath, and bronchial diastolic function were evaluated after administration of $200 \mu \mathrm{g}$ of salbutamol (GlaxoSmithKline Pharmaceuticals Ltd.). The procedure was performed according to the ATS/ESR guidelines [12].

\section{4-detector CT examination}

Imaging examinations were performed using a 64-detector CT scanner (SOMATOM Definition AS, Siemens, Erlangen, Germany) with subjects holding their breath at full inspiration in the supine position. Technical parameters were based on our prior study [13] .

All CT images were automatically analyzed using the FACT-Digital Lung software [14, 15]. The percentage of the wall area (\%WA) of different generations of bronchi in each lobe, the extent of emphysema in the whole lung, right lung, left lung, and emphysema heterogeneity index $(\mathrm{HI})$ were expressed according to our prior study $[13,15,16]$.

\section{Statistical analysis}

Statistical analysis was performed with SPSS 19.0 (IBM, Armonk, NY, USA). Two-sided $P$-values $<0.05$ were deemed statistically significant. Continuous data were tested for normality using the Kolmogorov-Smirnov test. Data meeting the normal distribution were expressed as mean \pm standard deviation and were analyzed using Student's test. Non-normally distributed data were expressed as median (range of 25th to 75th) and analyzed using the Mann-Whitney $U$ test. Binary logistic regression models were used to identify predictive factors for the carbon dioxide retention group using a backward stepwise method, with a probability value for entry of $P=0.10$ and removal of $P=0.05$.

\section{Results}

Comparison of blood gas analysis data and other clinical parameters between the groups

Blood gas analysis showed that $\mathrm{PaCO}_{2}$ in the carbon dioxide retention group was $49.5(46-57.75) \mathrm{mmHg}$, higher than 38 (35-41) $\mathrm{mmHg}$ in the non-retention group $(P<0.001)$. The $\mathrm{pH}$ in the carbon dioxide retention group was 7.39 (7.36-7.40), lower than $7.43(7.41-7.45)$ in the non-retention group $(P<0.001)$, while $\mathrm{PaO}_{2}$ was 69 (58-89) $\mathrm{mmHg}$ in the carbon dioxide retention group, lower than $76.5(67-85.5) \mathrm{mmHg}$ in the non-retention group $(P=0.018)$.

Compared with the non-carbon dioxide retention group, the number of hospitalizations for the carbon dioxide retention group increased significantly during the 12 months prior to the study $(P=0.013)$; $\mathrm{mMRC}$ also increased $(P=0.034)$; There was no significant statistical difference between the groups for age, smoking, number of comorbidities, body mass index, CAT score $(P>0.05)$ (Table 1).

\section{Comparison of traditional lung function and IOS parameters between the groups}

In traditional lung function tests, compared with the non-carbon dioxide retention group, the carbon dioxide retention group had lower $\mathrm{FEV}_{1}, \mathrm{FEV}_{1}$ \%pred, $\mathrm{FEV}_{1}$ / FVC, and $\mathrm{MMEF}_{25-75 \%}(P<0.001)$, and higher RV/TLC $(P=0.017)$.

In the IOS test, compared with the non-carbon dioxide retention group, the carbon dioxide retention group possessed higher total airway resistance $Z_{5 \% \text { pred }}$ and $\mathrm{R}_{5 \% \text { pred }}(P=0.004$ and 0.008 , respectively), and higher peripheral airway resistance parameters $R_{5}-R_{20}$ and $A x$ $\left(P=0.009\right.$ and $P=0.011$, respectively). $\mathrm{X}_{5}$ negative increase was more pronounced in the carbon dioxide retention group than the non-retention group $(P=0.022$; Table 2$)$.

The above results show that the airflow restriction in the retention group was more obvious; total airway resistance and peripheral airway resistance were higher.

\section{Comparison of $\mathrm{CT}$ parameters between the groups}

There was a statistical difference in total lung capacity, emphysematous index, and mean lung density between the groups. Compared to the non-carbon dioxide retention group, the carbon dioxide retention group had increased total lung volume [6106.56 (5113.8-6767.43) vs 5578.61 (4512.44-6459.67), $P=0.011]$, increased \%LAA $\mathrm{Lhole}_{\text {e }}[23.23$ (15.43-29.51) vs $18.02(11.83-25.83), P=0.007]$, and lower mean lung density $[-861.37(-878.99--834.07)$ vs -851.21 (-867.76--829.83), $P=0.043$ ] (Table 3). The above results show that the carbon dioxide retention group had more obvious increased lung volume and emphysema, and that pulmonary parenchyma damage was more pronounced (Figs. 1 and 2).

There were no statistical differences in $\% \mathrm{WA}_{\mathrm{RUL} 4-7}$, $\% \mathrm{WA}_{\mathrm{RML4} 4-7}, \% \mathrm{WA}_{\mathrm{RLL} 4-9}, \% \mathrm{WA}_{\mathrm{LUL4} 4-7}$, and \%WA $\mathrm{WLL4-9}_{\text {L }}$ between the groups $(P>0.05$; Additional file 1: Table S1).

\section{Factors influencing carbon dioxide retention}

Based on the results of the univariate analysis and their clinical significance, 6 parameters were entered into the 
Table 1 Demographic and clinical datas between the carbon dioxide retention and non-carbon dioxide retention COPD

\begin{tabular}{|c|c|c|c|}
\hline \multirow[t]{2}{*}{ Varias } & \multirow{2}{*}{$\begin{array}{l}\text { Carbon dioxide retention } \\
n=86\end{array}$} & \multirow{2}{*}{$\begin{array}{l}\text { Non-carbon dioxide retention } \\
n=144\end{array}$} & \multirow[t]{2}{*}{$p$ value } \\
\hline & & & \\
\hline Age, years & $65.3 \pm 9.43$ & $67.53 \pm 10.24$ & 0.102 \\
\hline pack years & $46.55 \pm 32.49$ & $41.62 \pm 26.96$ & 0.318 \\
\hline Number of hospitalizations in the past 12 months & $0(0-1.25)$ & $0(0-1)$ & $0.013^{*}$ \\
\hline Comorbidities & $1(0-1)$ & $1(0-2)$ & 0.369 \\
\hline $\mathrm{BMl}, \mathrm{kg} / \mathrm{m}^{2}$ & $22.97 \pm 3.61$ & $23.40 \pm 3.80$ & 0.449 \\
\hline CAT & $21(14-25)$ & $18.5(12.5-25)$ & 0.18 \\
\hline $\mathrm{mMRC}$ & $2(1-3)$ & $1(0-2)$ & $0.034^{*}$ \\
\hline WBC, ${ }^{*} 109 / L$ & $6.55(5.24-8.07)$ & $7.15(5.5-9.12)$ & 0.088 \\
\hline $\mathrm{N}, \%$ & $72.8(63.7-80.5)$ & $73(62.75-81.2)$ & 0.972 \\
\hline $\mathrm{E}, \%$ & $1.2(0.5-2.4)$ & $1.6(0.6-3.2)$ & 0.241 \\
\hline $\mathrm{HB}, \mathrm{g} / \mathrm{L}$ & $144(135-152)$ & $142(129.5-151)$ & 0.142 \\
\hline$P L T^{*} 109 / L$ & $155.5(125-202)$ & $169(135-218)$ & 0.057 \\
\hline $\mathrm{FIB}, \mathrm{g} / \mathrm{L}$ & $3.64(2.91-4.47)$ & $4.06(3.25-5.1)$ & $0.02^{*}$ \\
\hline D-Dimer & $0.89(0.58-1.1)$ & $0.87(0.59-1.24)$ & 0.843 \\
\hline CRP, mg/L & $3.29(3.28-13.15)$ & $11.3(3.28-36.3)$ & $0.001^{* *}$ \\
\hline PCT & $0.05(0.05-0.05)$ & $0.05(0.05-0.05)$ & 0.203 \\
\hline $\mathrm{PH}$ & $7.39(7.36-7.40)$ & $7.43(7.41-7.45)$ & $<0.001^{* * *}$ \\
\hline $\mathrm{PaO} 2, \mathrm{mmHg}$ & $69(58-89)$ & 76.5 (67-85.5) & $0.018^{*}$ \\
\hline $\mathrm{PaCO} 2, \mathrm{mmHg}$ & $49.5(46-57.75)$ & $38(35-41)$ & $<0.001^{* * *}$ \\
\hline
\end{tabular}

Abbreviations: BMI body mass index, GOLD Global Initiative for Chronic Obstructive Lung Disease, COPD chronic obstructive pulmonary disease, WBC white blood cell count, $N$ neutrophil, $E$ Eosinophils, HB Hemoglobin, PLT blood platelet count, FIB fibrinogen, CRP C-reactive protein, PCT Procalcitonin Note: ${ }^{*} p<0.05 ;{ }^{* *} p<0.01 ;{ }^{* * *} p<0.001$

Table 2 Comparison of traditional pulmonary function tests and pulsed oscillatory resistance determination between the carbon dioxide retention and non-carbon dioxide retention COPD

\begin{tabular}{llll}
\hline & Carbon dioxide retention $(n=86)$ & Non-carbon dioxide retention $(n=144)$ & $p$ value \\
\hline Z5\%pred & $185.9(154-216.65)$ & $162.4(131.35-199.6)$ & 0.004 \\
R5\%pred & $168(138.85-197.7)$ & $148(126.75-182.75)$ & 0.008 \\
R5 & $0.52(0.43-0.61)$ & $0.49(0.39-0.57)$ & 0.057 \\
R20\%pred & $123.4(105.75-139.55)$ & $117.2(104.3-135.6)$ & 0.236 \\
R20 & $0.32(0.29-0.375)$ & $0.33(0.29-0.37)$ & 0.764 \\
R5-R20 & $0.18(0.125-0.23)$ & $0.14(0.09-0.205)$ & 0.009 \\
X5 & $-0.24(-0.31--0.16)$ & $-0.19(-0.32--0.13)$ & 0.022 \\
Fres & $22(18.26-26.19)$ & $21.2(17.48-24.61)$ & 0.173 \\
Ax & $1.89(1.27-2.57)$ & $1.54(0.74-2.44)$ & 0.011 \\
FEV1 & $0.95(0.77-1.42)$ & $1.39(1.06-1.74)$ & $<0.001$ \\
FEV1\%pred & $34.25(25.4-47.8)$ & $51.45(40-61.7)$ & $<0.001$ \\
FEV1/FVC & $48.14(42.08-56.71)$ & $56.26(46.55-62.79)$ & $<0.001$ \\
MMEF75-25\%pred & $14.25(9.7-19.9)$ & $21.5(16.1-27.75)$ & $<0.001$ \\
DLCONA & $75.47 \pm 24.29$ & $80.13 \pm 24.34$ & 0.169 \\
RV/TLC & $59.44 \pm 10.11$ & $55.98 \pm 10.63$ & 0.017 \\
\hline
\end{tabular}

Abbreviations: PFT Pulmonary function test, FEV1 forced expiratory volume in $1 \mathrm{sec}$, FVC forced vital capacity, FEV1/FVC forced expiratory volume in 1 sec/forced vital capacity, $M M E F_{25-75 \%}$ maximal mid expiratory flow, $R V / T L C$ residual volume/total lung capacity, DLCO/NA ratio of carbon monoxide diffusion capacity to alveolar ventilation, \%Pred, of the predicted value, $Z_{5}$ Total respiratory impedance, $R 5$ resistance at $5 \mathrm{~Hz}, R_{20}$ resistance at $20 \mathrm{~Hz}, X_{5}$ reactance at $5 \mathrm{~Hz}$, Fres response frequency, Ax reactance area 
Table 3 Comparison of Emphysema variables between the carbon dioxide retention and non-carbon dioxide retention COPD

\begin{tabular}{|c|c|c|c|}
\hline Emphysema variables & Carbon dioxide retention & Non-carbon dioxide retention & $p$ value \\
\hline Volume whole & 6106.56 (5113.8-6767.43) & 5578.61 (4512.44-6459.67) & 0.011 \\
\hline$\%$ LAA whole & $23.23(15.43-29.51)$ & $18.02(11.83-25.83)$ & 0.007 \\
\hline Mean lung density whole & $-861.37(-878.99--834.07)$ & $-851.21(-867.76--829.83)$ & 0.043 \\
\hline Volume Right lung & $3180.79(2756.52-3578.41)$ & 3014.42 (2482.47-3488.95) & 0.047 \\
\hline$\% L_{A A}$ Right lung & $23.4(15.24-30.08)$ & $17.65(12.28-25.68)$ & 0.006 \\
\hline Mean lung density Right & $-859.2(-879.56--835.39)$ & $-851.14(-866.61--829.63)$ & 0.032 \\
\hline Volume Left lung & 2878.78 (2319.57-3221.92) & 2599.85 (2039.45-3039.15) & 0.003 \\
\hline$\%$ LAA Left lung & $23.39(14.8-29.1)$ & $18.83(11.65-26.32)$ & 0.008 \\
\hline Mean lung density Left & $-862.98(-876.01--837.3)$ & $-847.85(-870.33--826.79)$ & 0.039 \\
\hline $\mathrm{HI}$ whole & $0.09(-0.08-0.29)$ & $0.16(-0.02-0.32)$ & 0.169 \\
\hline $\mathrm{HI}$ Right lung & $0.15(-0.06-0.35)$ & $0.18(-0.02-0.38)$ & 0.458 \\
\hline $\mathrm{HI}$ Right lung & $-0.17(-0.41-0.05)$ & $-0.08(-0.28-0.11)$ & 0.079 \\
\hline
\end{tabular}

Abbreviations: \%LAA the extent of emphysema of CT attenuation value below -950 HU;MDE:Mean density of emphysema; Hl:emphysema heterogeneity index, when emphysemais equally distributed among the lobes or the full extent in the whole lung is $<1 \%$, $\mathrm{HI}$ is near zero; otherwise,HI = (\%LAAupper -\%LAAlower)/(\%LAAupper+\%LAAlower $)^{*} 100$

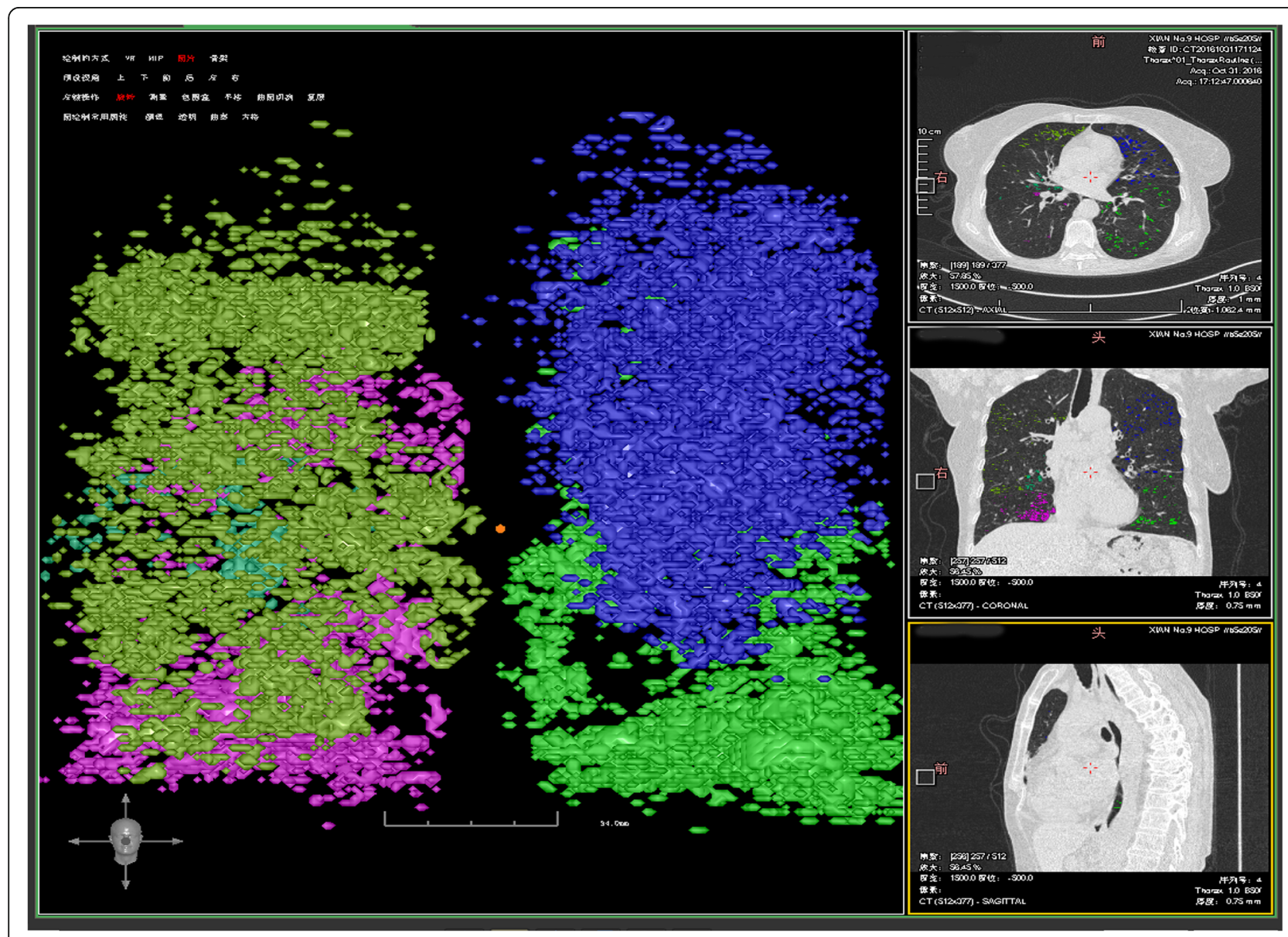

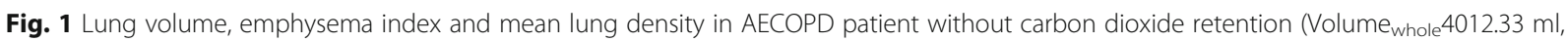
$\left.E_{\text {whole }} 9.82 \%, M_{\text {whole }}-808.26 \mathrm{Hu}\right)$ 


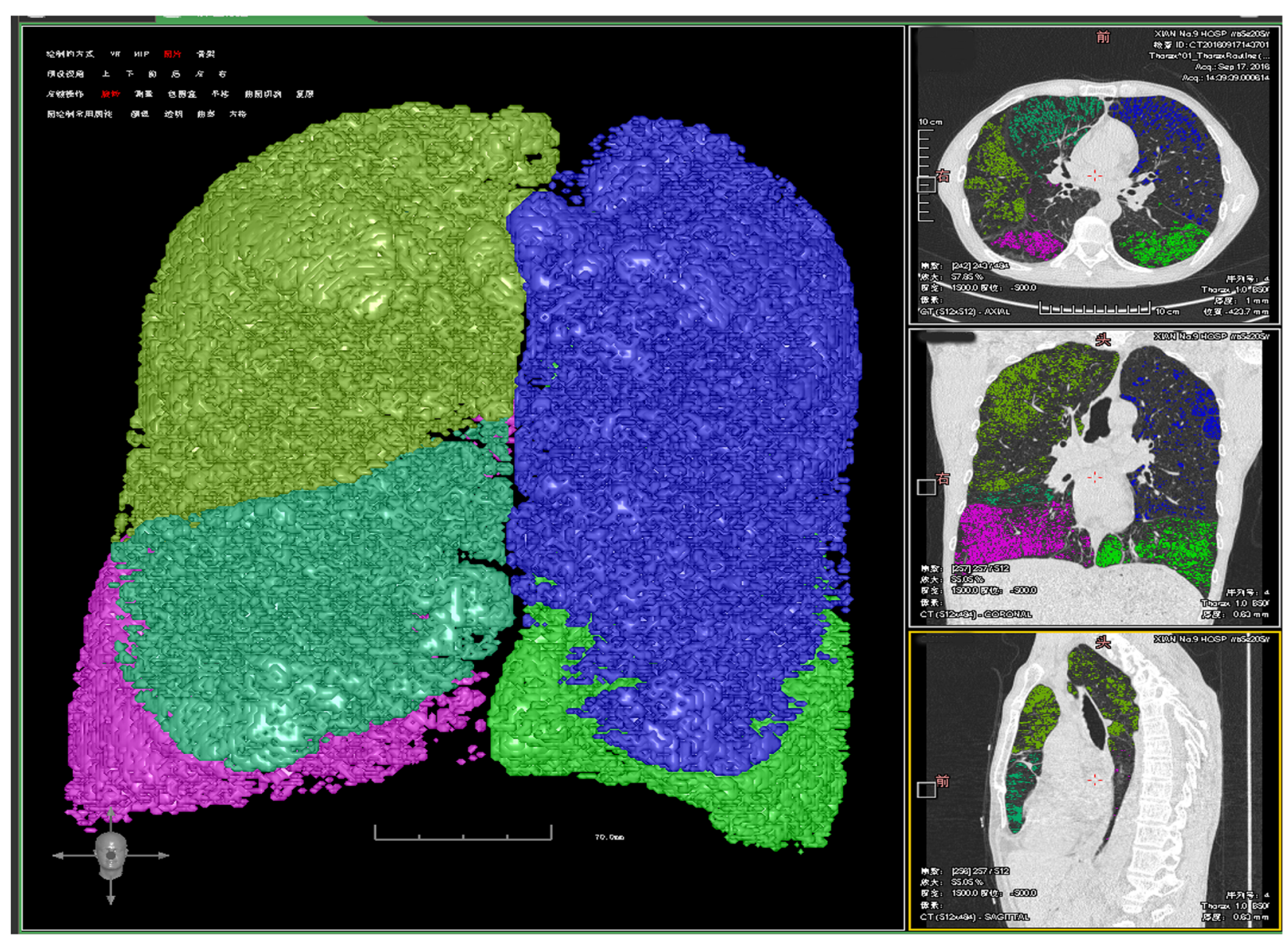

Fig. 2 Lung volume, emphysema index and mean lung density in AECOPD patient with carbon dioxide retention (Volume whole $6187.62 \mathrm{ml}$, El whole $15.17 \%$, MLD $_{\text {whole }}-851.18 \mathrm{Hu}$ )

logistics analysis: the number of hospitalizations because of AECOPD in the previous 12 months $(\geq 1)$, mMRC $(\geq 2)$, neutrophil ratio $(\geq 70 \%)$, X5 negative increase $(<0)$, whole lung emphysema index $(\mathrm{EI}>20 \%)$ and $\mathrm{FEV}_{1}(<1 \mathrm{~L})$. Logistic regression analysis, using the back stepwise method, showed that $\mathrm{FEV}_{1}<1 \mathrm{~L}$ and \% $\mathrm{LAA}_{-950 \mathrm{HU}}>20 \%$ were independent risk factors for carbon dioxide retention (Table 4). The predictive value of these two parameters for carbon dioxide retention was $69.4 \%$.

\section{Discussion}

COPD is a heterogeneous disease, and for the specific population included in this study, carbon dioxide retention indicates that the disease has progressed to the

Table 4 Logistic regression analysis of factors associated with carbon dioxide retention

\begin{tabular}{lll}
\hline & $P$ & OR $(95 \% \mathrm{Cl})$ \\
\hline FEV1 $<1 \mathrm{~L}$ & $<0.001$ & $4.011(2.216-7.262)$ \\
\%LAA-950Hu $>20 \%$ & 0.026 & $1.926(1.080-3.432)$ \\
\hline
\end{tabular}

decompensation phase of respiratory dysfunction. In terms of COPD treatment, this population therefore requires the most medical resources and tends to respond poorly to clinical treatment. Our study revealed the clinical, pulmonary function, and imaging features of patients who have carbon dioxide retention. The carbon dioxide retention group had more frequent hospital admissions for acute exacerbations in the 12 months prior to the study, more pronounced dyspnea symptoms, and lower arterial partial pressure of oxygen. Regardless of the traditional lung function or IOS test, the carbon dioxide retention group had poorer parameters, more obstructive airflow, and higher residual volume. In imaging, the carbon dioxide retention group had higher lung volume and emphysema index, and lower mean lung density. However, there was no difference in emphysematous distribution and multi-stage bronchial wall area. Our results showed that $\mathrm{FEV}_{1}<1 \mathrm{~L}$ and $\mathrm{EI}>20 \%$ can help predict the increased risk of COPD with carbon dioxide retention.

Studies from ECLIPSE suggest that the clinical manifestations of COPD vary widely, and the extent of airflow 
limitation cannot capture the heterogeneity of the disease [17]. $\mathrm{FEV}_{1}$ is not believed to reflect the whole picture of COPD and is not a reliable predictor of disease stage for specific individuals [18]. However, there is also the opinion [19] that $\mathrm{FEV}_{1}<1 \mathrm{~L}$ is an independent prognostic factor. Although FEV1 is generally expressed more accurately as a percentage of the predicted value, a fixed cutoff is assessed for limited airflow severity when FEV1 is much lower than normal, and we believe it to be reliable for clinical use. Our study also showed that $\mathrm{FEV}_{1}<1 \mathrm{~L}$ predicts the presence of carbon dioxide, which is especially useful for assessing COPD with chronic long-term carbon dioxide retention and to provide a reference for deciding on treatments like adjuvant ventilation, or for parameter selection as a follow-up step. Emphysema index is currently a more accepted imaging parameter for the assessment of COPD [20, 21] because of its reflection of both pathological and functional impairments. Our regression analysis showed that EI $>20 \%$ and $\mathrm{FEV}_{1}<1 \mathrm{~L}$ can be used to predict carbon dioxide retention, reflecting both pathological and functional impairments. O'Donnell [22] conducted a similar study using discriminant analysis and found that $\mathrm{FEV}_{1} /$ FVC rates, as well as vital capacity (\% predicted) or FVC (\% predicted), differentiated patients requiring mechanical ventilation from those who did not.

There are many phenotypes based on COPD [23], however, COPD with carbon dioxide retention has rarely been studied. Gas exchange in COPD is very complicated; the mechanism of carbon dioxide retention induced hypercapnia is the result of multiple pathological processes that are interwoven at varying degrees and affected by the disease process itself. In addition, the cellular and molecular details of lung tissue destruction are not completely understood [24]. The destruction of lung parenchyma mainly manifested as emphysema, accompanied by pulmonary vascular bed damage. Small airway remodeling and occlusion are other important outcomes of pathological damage. In acute exacerbation events, airway spasms, mucosal edema, and sputum cause increased airway obstruction and inflammation.

Chronic respiratory failure results in carbon dioxide retention due to respiratory insufficiency $[25,26]$, We found that there was a more severe airflow limitation in the carbon dioxide retention group. In the image data for this group, we found a more obvious increase in the lung volume and the emphysema index, and that the mean lung density was lower, suggesting that there was not only excessive expansion of dynamic lung, but also more physical damage to the lung involved in the pathological process.

Clinical strategies for AECOPD include: treatment of the primary disease, controlled oxygen therapy, and the use of an invasive or non-invasive ventilator to improve lung ventilation. Current clinical treatment is partial to improving lung ventilation, while putting less emphasis on changes in the pulmonary parenchyma. However, better carbon dioxide removal has been a topic of growing interest in recent years, and a new approach involves extracorporeal venous $\mathrm{CO}_{2}$ removal [27-29].

Carbon dioxide retention in the body can cause harm that is multi-system and widespread. Clinical emphasis is on the treatment of hypoxia, but there is an attitude of tolerance to carbon dioxide retention. Clinicians should recognize that carbon dioxide retention will increase the hypoxic damage to multiple tissues [30, 31]. Hypervolemic respiratory failure noninvasive ventilation (NIV) treatment is the primary method of clinical management and, based several large studies [32, 33], it is reasonable to use a higher level of partial pressure of carbon dioxide to determine NIV use. Our study focused on the parameters of pulmonary function and imaging that would be valuable when carbon dioxide retention was elevated, so the cutoff partial pressure of carbon dioxide was chosen as $45 \mathrm{mmHg}$.

The characteristics of COPD populations with carbon dioxide retention are typically not of concern. Most studies focus on the COPD populations based on pulmonary function grading. In contrast, our research is novel because we focused on a particular population with specific clinical features, and so were able to obtain some valuable results. However, the present study is not without limitations. It is only assumed that persistent carbon dioxide retention and transient carbon dioxide retention are different, but there are no observations for the longitudinal outcomes of these conditions. Secondly, the sample size was small. To address these issues, more research is needed to explore the features of carbon dioxide retention in patients with AECOPD.

\section{Conclusion}

The carbon dioxide retention COPD group had more airflow obstruction and higher residual volume, lung volume, and emphysema index, as well as lower mean lung density compared to the COPD group without carbon dioxide retention. FEV1 $<1 \mathrm{~L}$ and EI $>20 \%$ may be predictors of an increased risk of carbon dioxide retention.

\section{Additional file}

Additional file 1: Table S1. Comparison of wall areas between the carbon dioxide retention and non-carbon dioxide retention COPD groups. (XLSX $10 \mathrm{~kb}$ ) 


\section{Abbreviations}

\%Pred: of the predicted value; \%WA: the percentage of the wall area; the \%WA of different generations in each lobes were represented as \%WARUL47, \%WARML4-7, \%WARLL4-9, \%WALUL4-7, and \%WALLL4-9\%LAAthe extent of emphysema of $\mathrm{CT}$ attenuation value below - $950 \mathrm{HU}$; Ax: reactance area; BMl: body mass index; COPD: chronic obstructive pulmonary disease; $C T$ : computed tomography; DLCONA: ratio of carbon monoxide diffusion capacity to alveolar ventilation; E: eosinophil; FEV1: forced expiratory volume in one second; FEV1/FVC: forced expiratory volume in one second/forced vital capacity; Fres: resonant frequency; FVC: forced vital capacity; GOLD: Global Initiative for Chronic Obstructive Lung Disease; HB: Hemoglobin; HI: emphysema heterogeneity index; MED: mean emphysema density; MMEF25-75\%: maximal mid expiratory flow; mMRC: modified Medical Research Council; N: neutrophil; NIV: noninvasive ventilation; PFT: Pulmonary function test; PLT: blood platelet count: R20: resistance at $20 \mathrm{~Hz}$; R5: resistance at $5 \mathrm{~Hz}$ : RV/TLC: residual volume/ total lung capacity; WBC: white blood cell count; X5: reactance at $5 \mathrm{~Hz}$; Z5: Total respiratory impedance

\section{Funding}

This research was supported by the Social Development Science Research Project of Shaanxi Province (No. 2016SF-151) and Xi'an Science and Technology Project (No. 2016045SF / YX01). Funders had no role in the study design, data collection and analysis, decision to publish, or in the preparation of the manuscript.

\section{Availability of data and materials}

The datasets used and/or analysed during the current study are available from the corresponding author on reasonable request.

\section{Authors' contributions}

XW conceived and designed the study, designed, performed and analyzed the experiments, and wrote the paper. QD, JTR, JYM, LB, JYL, and MQ carried out the data collection, data analysis, and revised the paper. YN and YMG designed the study and revised the paper. All authors read and approved the final manuscript.

\section{Ethics approval and consent to participate}

The study protocol was approved by the Ninth Hospital of Xi'an Affiliated Hospital of Xi'an Jiaotong University Ethics Committee (No.2014001). Written informed consent was obtained from all patients.

\section{Consent for publication}

The personal information involved in the image has been obtained with the consent of the individual.

\section{Competing interest}

The authors declare that they have no competing interests.

\section{Publisher's Note}

Springer Nature remains neutral with regard to jurisdictional claims in published maps and institutional affiliations.

\section{Author details}

'Department of Radiology, Xi'an Jiaotong University Medical College First Affiliated Hospital, Xi'an, China. ${ }^{2}$ Department of Respiratory Medicine, The Ninth Hospital of Xi'an Affiliated Hospital of Xi'an Jiaotong University, Xi'an, China. ${ }^{3}$ Department of Radiology, The Affiliated Hospital of Shaanxi University of Traditional Chinese Medicine, Xianyang, Shaanxi, China. ${ }^{4}$ Department of Respiratory Medicine, Central Hospital of Xi'an Affiliated Hospital of Xi'an Jiaotong University, Xi'an, Shaanxi, China. ${ }^{5}$ Department of Radiology, Shaanxi Provincial People's Hospital, Xi'an, China.

Received: 16 March 2018 Accepted: 16 July 2018

\section{Published online: 31 July 2018}

\section{References}

1. Lozano R, Naghavi M, Foreman K, Lim S, Shibuya K, Aboyans V, Abraham J, Adair T, Aggarwal R, Ahn SY, et al. Global and regional mortality from 235 causes of death for 20 age groups in 1990 and 2010: a systematic analysis for the global burden of disease study 2010. Lancet. 2012;380(9859):2095-128.
2. Vos T, Flaxman AD, Naghavi M, Lozano R, Michaud C, Ezzati M, Shibuya K, Salomon JA, Abdalla S, Aboyans V, et al. Years lived with disability (YLDs) for 1160 sequelae of 289 diseases and injuries 1990-2010: a systematic analysis for the global burden of disease study 2010. Lancet. 2012;380(9859):2163-96.

3. Yin P, Wang H, Vos T, Li Y, Liu S, Liu Y, Liu J, Wang L, Naghavi M, Murray CJ, et al. A subnational analysis of mortality and prevalence of COPD in China from 1990 to 2013: findings from the global burden of disease study 2013. Chest. 2016;150(6):1269-80.

4. Liu S, Zhou Y, Liu S, Chen X, Zou W, Zhao D, Li X, Pu J, Huang L, Chen J, et al. Association between exposure to ambient particulate matter and chronic obstructive pulmonary disease: results from a cross-sectional study in China. Thorax. 2017;72(9):788-95.

5. From the Global Strategy for the Diagnosis, Management and Prevention of COPD, Global Initiative for Chronic Obstructive Lung Disease (GOLD) [http://goldcopd.org/gold-2017-global-strategy-diagnosismanagement-prevention-copd/]. Accessed 12 Feb 2017.

6. Chae EJ, Seo JB, Song J-W, Kim N, Park B-W, Lee YK, Oh Y-M, Lee SD, Lim SY. Slope of emphysema index: an objective descriptor of regional heterogeneity of emphysema and an independent determinant of pulmonary function. Am J Roentgenol. 2010;194(3):W248-55.

7. Choromanska A, Macura KJ. Role of computed tomography in quantitative assessment of emphysema. Pol J Radiol. 2012;77(1):28-36.

8. Yamasawa W, Tasaka S, Betsuyaku T, Yamaguchi K. Correlation of a decline in aerobic capacity with development of emphysema in patients with chronic obstructive pulmonary disease: a prospective observational study. PLoS One. 2015;10(4):17.

9. Costello R, Deegan P, Fitzpatrick M, McNicholas WT. Reversible hypercapnia in chronic obstructive pulmonary disease: a distinct pattern of respiratory failure with a favorable prognosis. Am J Med. 1997;102(3):239-44.

10. Tsuboi T, Oga T, Sumi K, Machida K, Ohi M, Chin K. The importance of stabilizing $\mathrm{PaCO} 2$ during long-term non-invasive ventilation in subjects with COPD. Intern Med. 2015:54(10):1193-8.

11. Cai BQ, Cai SX, Chen RC, Cui LY, Feng YL, Gu YT, Huang SG, Liu RY, Liu GN, Shi $\mathrm{HZ}$, et al. Expert consensus on acute exacerbation of chronic obstructive pulmonary disease in the People's Republic of China. Int J Chron Obstruct Pulmon Dis. 2014;9:381-95.

12. M MR, H J, B V. ATS/ERS task force: standardisation of spirometry. Eur Respir J. 2005;26(2):319-38.

13. Wei X, Ma Z, Yu N, Ren J, Jin C, Mi J, Shi M, Tian L, Gao Y, Guo Y. Risk factors predict frequent hospitalization in patients with acute exacerbation of COPD. Int J Chron Obstruct Pulmon Dis. 2018;13:121-9.

14. Pu J, Fuhrman C, Good WF, Sciurba FC, Gur D. A differential geometric approach to automated segmentation of human airway tree. IEEE Trans Med Imaging. 2011;30(2):266-78.

15. Yu N, Xin X-M, Li Y, Ma J-C, Gao J-G, Jin C-W, Guo Y-M. Effect of computed tomography dose on quantitative measurement and automated segmentation of airway tree. J Med Imaging and Health Informatics. 2015; 5(7):1519-23.

16. Yu N, Wei X, Li Y, Deng L, Jin C-W, Guo Y. Computed tomography quantification of pulmonary vessels in chronic obstructive pulmonary disease as identified by 3D automated approach. Medicine. 2016;95(40):e5095.

17. Agusti A, Calverley PM, Celli B, Coxson HO, Edwards LD, Lomas DA, MacNee W, Miller BE, Rennard S, Silverman EK, et al. Characterisation of COPD heterogeneity in the ECLIPSE cohort. Respir Res. 2010;11:122.

18. Han MK, Agusti A, Calverley PM, Celli BR, Criner G, Curtis JL, Fabbri LM Goldin JG, Jones PW, MacNee W, et al. Chronic obstructive pulmonary disease phenotypes the future of COPD. Am J Respir Crit Care Med. 2010; 182(5):598-604.

19. Gorzelak K, Sliwinski P, Tobiasz M, Gorecka D. Zielinski J: [predictors of survival in patients with chronic obstructive pulmonary disease with moderate hypoxemia]. Pol Arch Med Wewn. 1995;93(6):491-7.

20. Mohamed Hoesein FA, de Hoop B, Zanen P, Gietema H, Kruitwagen CL, van Ginneken B, Isgum I, Mol C, van Klaveren RJ, Dijkstra AE, et al. CT-quantified emphysema in male heavy smokers: association with lung function decline. Thorax. 2011;66(9):782-7.

21. Xie M, Wang W, Dou S, Cui L, Xiao W. Quantitative computed tomography measurements of emphysema for diagnosing asthma-chronic obstructive pulmonary disease overlap syndrome. Int J Chron Obstruct. Pulmon Dis. 2016;11:953-61.

22. O'Donnell DE, Parker CM. COPD exacerbations center dot 3: pathophysiology. Thorax. 2006;61(4):354-61. 
23. Chen Y. Heterogeneity of acute exacerbation of chronic obstructive pulmonary disease in clinical manifestations. Zhonghua jie he he hu xi za zhi = Zhonghua jiehe he huxi zazhi $=$. Chinese J Tuberculosis and Respiratory Dis. 2014;37(4):244-6.

24. Taraseviciene-Stewart L, Voelkel NF. Molecular pathogenesis of emphysema. J Clin Investig. 2008;118(2):394-402.

25. Schonhofer B. Noninvasive ventilation in patients with persistent hypercapnia. Medizinische Klinik, Intensivmedizin und Notfallmedizin. 2015; 110(3):182-7.

26. Brill SE, Wedzicha JA. Oxygen therapy in acute exacerbations of chronic obstructive pulmonary disease. Int J Chron Obstruct Pulmon Dis. 2014;9: 1241-52.

27. Kreppein $U$, Litterst $P$, Westhoff $M$. Hypercapnic respiratory failure. Pathophysiology, indications for mechanical ventilation and management. Medizinische Klinik-Intensivmedizin Und Notfallmedizin. 2016;111(3):196-201.

28. Burki NK, Mani RK, Herth FJF, Schmidt W, Teschler H, Bonin F, Becker H, Randerath WJ, Stieglitz S, Hagmeyer L, et al. A novel extracorporeal CO(2) removal system: results of a pilot study of hypercapnic respiratory failure in patients with COPD. Chest. 2013;143(3):678-86.

29. Cove ME, MacLaren G, Federspiel WJ, Kellum JA. Bench to bedside review: Extracorporeal carbon dioxide removal, past present and future. Crit Care. 2012:16(5):232

30. Yasuo M, Mizuno S, Kraskauskas D, Bogaard HJ, Natarajan R, Cool CD, Zamora M, Voelkel NF. Hypoxia inducible factor-1 alpha in human emphysema lung tissue. Eur Respir J. 2011;37(4):775-83.

31. Selfridge AC, Cavadas MAS, Scholz CC, Campbell EL, Welch LC, Lecuona E, Colgan SP, Barrett KE, Sporn PHS, Sznajder JI, et al. Hypercapnia suppresses the HIF-dependent adaptive response to hypoxia. J Biol Chem. 2016;291(22): $11800-8$.

32. Kohnlein T, Windisch W, Kohler D, Drabik A, Geiseler J, Hartl S, Karg O, LaierGroeneveld G, Nava S, Schonhofer B, et al. Non-invasive positive pressure ventilation for the treatment of severe stable chronic obstructive pulmonary disease: a prospective, multicentre, randomised, controlled clinical trial. Lancet Respir Med. 2014;2(9):698-705.

33. Murphy PB, Rehal S, Arbane G, Bourke S, Calverley PMA, Crook AM, Dowson L, Duffy N, Gibson GJ, Hughes PD, et al. Effect of home noninvasive ventilation with oxygen therapy vs oxygen therapy alone on hospital readmission or death after an acute COPD exacerbation: a randomized clinical trial. Jama. 2017:317(21):2177-86.

Ready to submit your research? Choose BMC and benefit from:

- fast, convenient online submission

- thorough peer review by experienced researchers in your field

- rapid publication on acceptance

- support for research data, including large and complex data types

- gold Open Access which fosters wider collaboration and increased citations

- maximum visibility for your research: over $100 \mathrm{M}$ website views per year

At $\mathrm{BMC}$, research is always in progress.

Learn more biomedcentral.com/submissions 